\title{
Individual Differences in Second Language Acquisition Styles from the Perspective of Theory of Multiple Intelligences
}

\author{
Bowen Jia ${ }^{1, \dagger}$, Jingying Qian ${ }^{2, \dagger}$, Wanzhuo Song ${ }^{3, *, \dagger}$ \\ ${ }^{1}$ Jiangxi Agricultural University, Nanchang, Jiangxi, China \\ ${ }^{2}$ SEGI University \& Colleges, Malaysia \\ ${ }^{3} X i$ 'an International University, Xi'an, Shaanxi, China \\ *Corresponding author. Email: songwanzhuo@xaiu.edu.cn \\ Those authors contributed equally.
}

\begin{abstract}
In recent years, the theory of multiple intelligences (MI) proposed by Howard Gardner has received much discussion among educational scholars, and research on the connections between MI theory and second language teaching has become increasingly popular. However, there is a paucity of research on the various reasons why learners achieve different learning outcomes in second language acquisition due to the use of different intelligences. This article presents a study of learners' individual styles of second language acquisition in the context of MI theory. In terms of methodology, first, this study used an online questionnaire to obtain the percentage of different intelligences used in second language acquisition by respondents aged from 17 to 44 . The data from the questionnaire showed that some of the respondents used the same intelligence for second language acquisition, but achieved different learning outcomes. Therefore, factors such as learners' family backgrounds, educational backgrounds, and personal learning habits were considered as various reasons for these differences to be further explored. Second, the three online interviews conducted with this group of respondents were another method used in this study. The final data analysis revealed that personal factors such as family background and educational background did not determine the effectiveness of learners' second language acquisition, but rather the type of intelligence they adopted was considered as the key factor.
\end{abstract}

Keywords: multiple intelligences (MI); second language acquisition; second language teaching; learning habits.

\section{INTRODUCTION}

Second Language Acquisition (SLA) usually refers to the acquisition of any other Language after the Acquisition of one's first Language. As an important branch of applied linguistics, second language acquisition (SLA) mainly studies the process and results of people's learning of a second language. Its purpose is to objectively describe and scientifically explain language learners' language competence and communicative competence.

Since the beginning of this century, with the development of economic globalization and network information, as well as the deepening of global cultural interconnection and international cooperation, mastering a second language is becoming increasingly important
[1]. More and more people choose to learn a second language, and therefore, second language acquisition has boomed in recent years. In this field, theories, practices and teaching studies on second language acquisition have also emerged one after another [2]. For example, Li demonstrates that an increasing number of Chinese teenagers aged 15 to 25 tend to go to Englishspeaking countries to improve their English fluency and language ability [3]. They believe that an immersive English environment is good for their second language acquisition.

People are used to studying second language acquisition from social, psychological and linguistic perspectives, so it is generally regarded as a multidisciplinary and mixed study to provide 
opportunities for many scholars to enrich their research achievements and theoretical innovations in the field of second language acquisition. On the one hand, second language acquisition research focuses on the characteristics and development of second language learning, on the other hand, it describes the commonness and individuality of learners in second language learning and analyses the internal and external factors that affect their second language learning [4]. But at the same time, there are also many deficiencies in the learning effect and teaching methods of learners, such as the complexity and inconsistency of the context environment, the irregular use of language, etc., according to $\mathrm{Wu}[5]$. Therefore, the research on second language acquisition has a great space to be explored by scholars.

As a modern research field, SLA is generally believed to date back to the late 1960s. As early as the first few years of the 20th century, the Book Bilingual for children published. In the early stage of SLA (1960s to 1980s), the Book Bilingual tried to establish a connection between behaviourist psychology and structural linguistics and problems in foreign language learning, then turned to the analysis of learners' mistakes in the process of learning, and then focused on markedness theory and applied universal language jurisprudence in second language. After the 1980s, Ellis believes that SLA has made remarkable development in the following three aspects: the research scope has been broadened, no longer confined to grammar research, and began to gradually study learners' characteristics from the perspective of social culture and sociolinguistics [6]. In addition, Chomsky's application of universal grammar theory and connectionism in cognitive theory, and the research methods are constantly innovated.

Different scholars have different classifications of research contents, but they are generally divided into language factors and learner factors. Language factors mainly include language input, learners' language processing and so on; Learner factors include educational background, educational environment, age, gender and so on. These factors will affect the second language learning process. Generally speaking, the former studies tend to SLA itself or improve theoretical knowledge, and there are two categories of factors affecting second language. However, there is no research on whether the process of second language acquisition is related to individual differences in personal style.

Acquiring a second language through eight human intelligence structures in multiple intelligences theory, explains why learners can acquire a second language, takes learners as the research object, and analyses the influence of internal and external factors, including age, gender; environment, education background, learning ability and so on. In the process of learners' acquisition, and explores and studies the individual differences of second language acquisition styles.

In recent years, academic discussions around the theory of multiple intelligences (MI) have become more and more popular. Multiple intelligences refer to the basic intelligences that human beings use in acquiring information, gaining knowledge, communicating with others, participating in social activities and other life behaviours. Howard Gardner first proposed the theory of multiple intelligences, and divided MI into eight main types: verbal-linguistic, logical-mathematical, visualspatial, bodily-kinesthetic, musical, interpersonal, intrapersonal, and naturalistic intelligence [7]. According to Gardner, the theory of MI can be seen as a new means of conceptualizing and evaluating human intelligence. Also, each individual has a different ability to perform with respect to the particular intelligence they possess [8].

It is evident that multiple intelligences play a significant role in human learning and life. Educator Zhixian Zhong has mentioned that each learner has his or her own advantageous intellectual domain and intellectual characteristics. The application of MI in teaching encourages learners to fully utilize and develop their superior intelligence structures, and also provides an opportunity for diversified and open development of teaching. Meanwhile, many linguistic scholars pointed out that the theory of MI is closely related to learners' SLA and largely influences the effectiveness of their SLA [9]. For the vast majority of Chinese students, their second language is English. English professor Yuanzhen Huang suggests that the theory of MI is tightly correlated with modern English teaching theory. Integrating the theory of MI into English classrooms facilitates the optimization of English teaching and learning [10].

Although many scholars have explicitly mentioned that the theory of MI has a strong impact on learners' SLA, there is a paucity of research on the common types of intelligences, learning styles, and differences in learners' acquisition outcomes when they engage in SLA. Therefore, the current article initiated this research to investigate the individual differences in learners' SLA in the context of MI theory.

\section{METHODOLOGY}

In this research, 2 methods have been utilized to collect data: 1) a survey questionnaire 2) an online interview. The rationale and steps of the two methods used for data collection will be explained in detail in the following pages. 


\subsection{Questionnaire}

First, a questionnaire entitled "An investigation of learners' second language acquisition styles in the context of Theory of Multiple Intelligences" was designed and distributed through "Wenjuan.com". In this questionnaire, a total of seven questions were set, consisting of one single choice, three short answer and two multiple choice questions.

The titles of the seven questions that were put into the questionnaire were:

1. What is your age? (Single-choice question)

2. What's your major? (Short answer question)

3. How much do you know about Theory of Multiple Intelligences? (Single-choice question)

4. What is the basic intelligence that you usually use when you are acquiring a second language? (Multiple choice question)

5. Please brief describe how you use your chosen intelligence for second language acquisition. (Short answer question)

6. What are the benefits when you use your chosen intelligence for second language acquisition? (Short answer question)

7. What kind of standardized English test have you taken? What is your best score of the test? (Multiple choice question)

In order to find out the various levels of English of the respondents, the 7th question has been added, which is asking the respondents to choose the standardized English test (IELTS, TOEFL, GRE, College English Band 4 and Band 6, Others) they have already taken and write down their best score of such test. In this way, it is much clearer to distinguish what intelligence is used for second language acquisition respectively by learners who learn well and those who do not learn well. In addition, if the same intelligence is used for second language acquisition, but there are differences in learning outcomes, then other elements that contribute to the differences need to be further explored.

\subsection{Interview}

Second, a web-based interview was conducted with respondents who used the same intelligence for second language acquisition but achieved different learning outcomes, so as to identify and understand the various factors that contributed to their differences. This interview was carried out by using WeChat for online messaging. A total of four questions were set for this interview, and three questionnaire respondents were selected as interviewees. Consistently, all three interviewees used verbal-linguistic intelligence for second language acquisition and all took the IELTS test, but their IELTS exam scores differed. The basic information of the interviewees such as their names, ages, and occupations were collected and included. The full interview was recorded in transcript form and inserted into the following pages:

\section{Transcript 1}

The first interviewee is a 21 years old girl and is currently a third year undergraduate student studying in Australia. Her best IELTS test score is 6 .

Interviewer: First of all, how old were you when you started acquiring a second language? Which is your second foreign language?

Interviewee 1: My second foreign language is English, and I started learning it in elementary school.

Interviewer: Okay, so let me ask you the second question. Does everyone in your family speak English? In other words, what is the English background in your family?

Interviewee 1: My parents don't speak any English at all, and there is no bilingual background in my family at all.

Interviewer: I see, let's move on to the third question. Have you ever taken any English classes outside of school? If so, what kind of content do they teach?

Interviewee 1: I have attended extra-curricular English tutoring, focusing on content about phonetics and phonology.

Interviewer: Last question, in addition to regular classroom instruction in compulsory English learning, does your school conduct any other teaching activities to support second language acquisition? If so, what were those activities like?

Interviewee 1: When I was in elementary school, my school hired a foreign teacher to teach us lessons. I think taking foreign teachers' classes helped me a lot in my spoken English.

Interviewer: Thank you for your participation in this interview.

\section{Transcript 2}

The second interviewee is a female senior majoring in business English in a university of China, who has got 7.5 in IELTS test.

Interviewer: First, which is your second foreign language and how old were you when you started acquiring a second language?

Interviewee 2: It's English, and I started learning it about 5 or 6 years old. 
Interviewer: Okay, so let me ask you the next question. Does everyone in your family speak English? In other words, what is the English background in your family?

Interviewee 2: All the family members in my family don't speak English, and there is no bilingual background in my family.

Interviewer: I see, now I'd like to ask you the third question. Have you ever taken any English classes outside of school? If so, what kind of content do they teach?

Interviewee 2: Yes, I have attended extra-curricular English courses with many of my peers since elementary school, these courses mainly focused on content about words and grammar.

Interviewer: Okay, last question, in addition to regular classroom instruction in compulsory English learning, did your school conduct any other teaching activities to support second language acquisition? If so, what were those activities like?

Interviewee 2: I remembered when I was in the secondary school, there was an annual European and American Classic Drama Performance Competition in our school. Our teachers always helped us to choose the drama and gave us guidance.

Interviewer: Thank you very much for your cooperation in this interview.

\section{Transcript 3}

The third interviewee is a 21-year-old female senior majoring in English in a University of China. Her best IELTS test score is 6.5 .

Interviewer: To begin with, what is your second foreign language? How old did you start learning a second language?

Interviewee 3: My second language is English, and I began to learn it when I was five years old.

Interviewer: Well, let's move on to the second question. About your educational background, can everyone in your family speak English or are you in a bilingual family?

Interviewee 3: I have no bilingual background, but my parents can speak a little English and can teach me how to spell English words when I was young.

Interviewer: That's great! let's move on to the third question. Have you ever taken any English classes outside of school? If so, what kind of content do they teach?

Interviewee 3: When I was still in primary school, I had an extracurricular English tutorial class. The teacher would teach our new concept English and word shorthand.
Interviewer: I see. Last question, in addition to regular classroom instruction in compulsory English learning, did your school conduct any other teaching activities to support second language acquisition? If so, what were those activities like?

Interviewee 3: Our school often holds many extracurricular activities to support second language acquisition. When I first went to college, the school had an English corner, and foreign teachers from different countries will communicate with students. In addition, our school has held a Model United Nations competition in the past two years to improve students' oral skill.

Interviewer: Thank you very much for your valuable answers.

\section{RESULT}

\section{For questionnaire:}

As for now 35 responses have been collected for the first 6 questions. The majority of respondents are age range of 17-44 years old. The average age of the respondents was around 22 years old and the standard deviation of age is 4.95 . It should be noted that the questionnaire asked for the names and ages of the respondents. However, according to the principle of confidentiality, the questionnaire designers will maintain the privacy of their basic personal information. After preliminary collection and analysis of the data, the results are inserted below in the form of a graph.

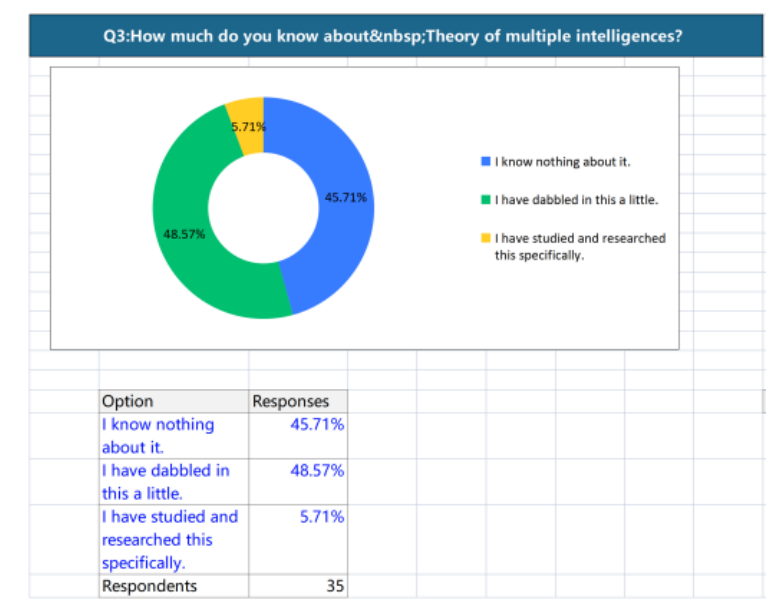

Figure 1 Number of people who understand the theory of Multiple Intelligences 


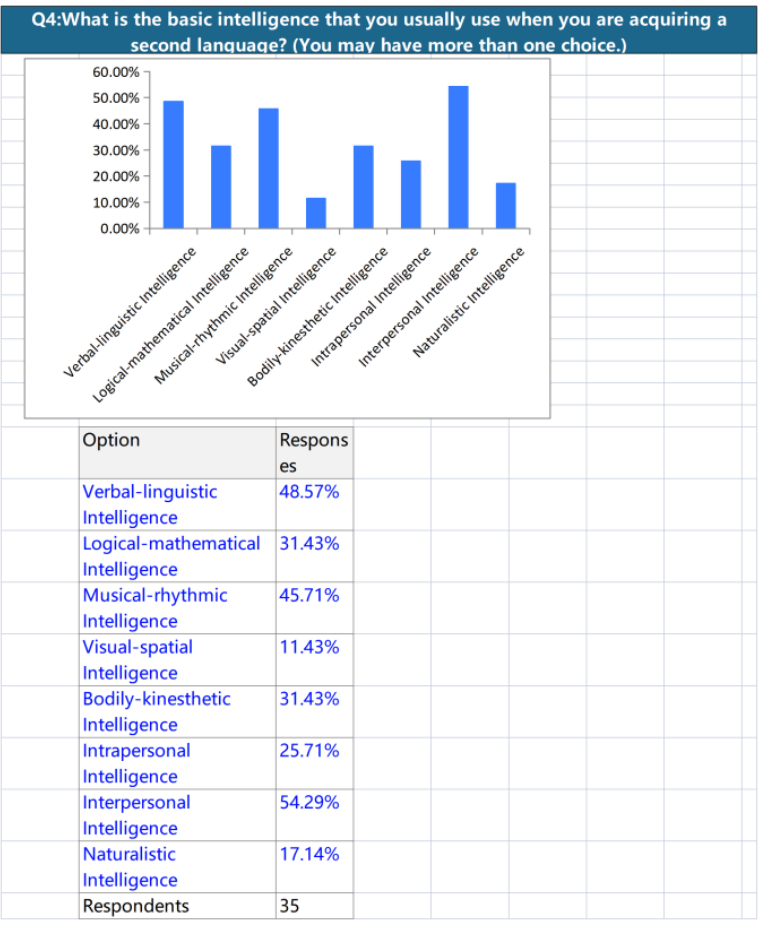

Figure 2 Proportion of foreign learners using different intelligence

The following findings can be drawn from the graph:

1. The proportion of respondents who are completely unaware of Theory of MI is almost equal to those who are slightly familiar with it, and few have studied it in depth.

2. Using interpersonal intelligence for second language acquisition accounts for the largest proportion with $54.29 \%$, while using verbal-linguistic and musicalrhythmic intelligence for second language acquisition is very close, with $48.57 \%$ and $45.71 \%$ respectively.

Regarding the 7th question:

1. The percentage of respondents who had taken IELTS tests was the same as that of those who had taken other tests, at $40 \%$.

2. The percentage of respondents who had taken CET- 4 and CET- 6 tests was the highest, accounting for $60 \%$ of the total number of respondents.

3. Among those who responded, nobody had taken TOEFL or GRE exams.

4. There are differences in the scores achieved by respondents taking the same test, for example, the highest score among respondents taking the IELTS test is 7 and the lowest score is 5 .

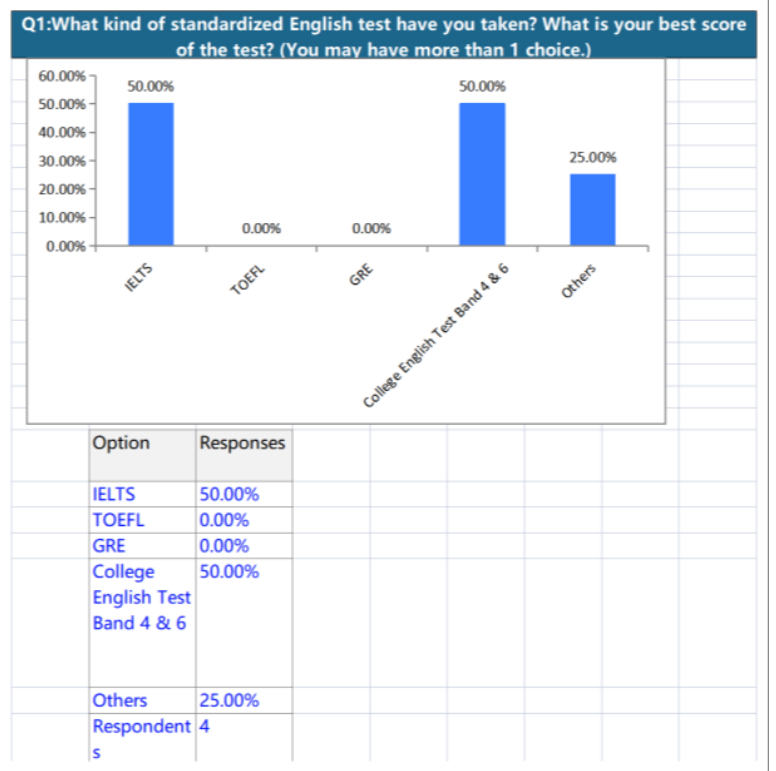

Figure 3 English proficiency assessment of respondents

\section{For interview:}

After summarizing all the transcripts of the interviews, the following key findings emerged:

1. All three interviewees were 21-year-old Chinese females studying at the undergraduate level.

2. All three interviewees had started learning a second language at about the elementary school level (5-7 years old), and their second language was English.

3. In terms of family background, none of the three interviewees were bilingual, and none of their parents spoke much English.

4. All three interviewees participated in extracurricular English tutoring activities, mainly extracurricular classes.

5. The IELTS scores of the three interviewees were ranked as follows: Interviewee 1 (6) < Interviewee 3 (6.5) < Interviewee 2 (7.5)

6. Interviewee 1 participated in English outreach activities conducted by the school (foreign language classes) only in her primary school years. Interviewee 2 participated in English outreach activities not only in elementary school, but also in English drama performances in secondary school. Interviewee 3 participated in some English outreach activities only in college.

\section{DISCUSSION}

\section{For questionnaire:}

Drawing from the data, the following main points could be summarized: 1) Most of the respondents are at the superficial stage of understanding the theory of 
multiple intelligences; 2) As far as the data is concerned, all of the 8 intelligences are applied when performing second language acquisition. 3) Many respondents are combining two or more intelligences for second language acquisition. 4) When using the same intelligence for second language acquisition, there are differences in learners' learning outcomes. 5) Gender, age, family context, educational context and other factors can be considered effective in influencing the outcome of second language acquisition and this need to be further investigated in the follow-up work. 6) Even if some people use the same intelligence, they learn in different specific ways and approaches. 7) Among the eight intelligences, interpersonal intelligence, verballinguistic intelligence and musical-rhythmic intelligence account for the top three, indicating that people prefer more external ways to interact with the outside world to help them learn a second language, compared with naturalistic intelligence and intrapersonal intelligence. 8) When answering the results of using eight intelligences to assist second language acquisition, people lay more emphasis on the improvement of learning efficiency and understanding of knowledge.

\section{For interview:}

According to the conclusion answered by the interviewee, it can be concluded that the three interviewees have the same age and gender, and the age stage receiving English is also similar. According to the IELTS scores of the three interviewees as the standard to measure their English level, the English level of the three interviewees is different, even if their educational background is similar, that is, not all bilingual families have participated in extracurricular tutoring and activities on second language learning held by the school. Therefore, internal and external factors (age, gender, educational background, educational environment) cannot be considered as the reasons for the differences in second language level. Under such conditions, the theory of multiple intelligences may become the main factor affecting the English level of the three interviewers to varying degrees.

\section{CONCLUSION}

The theory of multiple intelligence and individual differences opens up the vision of studying foreign language teaching. Under the guidance of the theory of multiple intelligence and individual differences, teachers should pay more attention to the differences between different learners and strive to develop teaching strategies for different learners for their own development. Foreign language learners are the subject of foreign language learning and the object of foreign language teaching. Foreign language teaching needs to teach students in accordance with their aptitude. More attention should be paid to the guidance of law study to solve the difficulties brought by individual differences and teachers should help people make the best of their talents. In short, this paper investigates the individual differences of learners' second language acquisition styles through the theory of multiple intelligences, and verifies the important factors for the differences in learners' learning effects. Based on the theory of multiple intelligences, this paper analyses the style of second language acquisition, explores the individual differences of second language acquisition, and obtains the enlightenment and guidance for second language learning.

\section{REFERENCES}

[1] Y. Guo \& S. Liu. (2021). The Ideal and Reality of "Global Language Governance" in the PostEpidemic Era: A review of the first Global Language Governance Forum. Foreign Languages in China (04),108-111.

[2] H. Jia. (2021). Research on innovative strategies of second Language acquisition theory in foreign language teaching under the Background of "One Belt and One Road" initiative. Journal of Anhui Electronic Information Vocational And Technical College

[3] C. Li. (2021). Performance data of second language learners in different learning environments. Modern Communication (14),43-45.

[4] Z. Niu. (2018). The development of second language acquisition in recent years. Northern Literature (17),230.

[5] R. Wu. (2010). Second Language Acquisition Strategies in a Globalized Network Language Environment: from the perspective of autonomous learning. Science and Education Guide (Mid-day) (04), 21-22+27.

[6] R. Ellis. (1986). Understanding second language acquisition [M]. Oxford: Oxford University Press.

[7] H. Gardner. (1987). The Theory of Multiple Intelligences. Annals of Dyslexia, 37, 19-35.

[8] H. Gardner, \& T. Hatch. (1989). Educational Implications of the Theory of Multiple Intelligences. Educational Researcher, 18(8), 4 10.

[9] Z. Zhong. (2004). Multiple intelligences theory and educational technology. E-education Research (3), 7-11.

[10] Y. Huang. (2003). On the integration of multiple Intelligences theory and English Teaching. Curriculum, Teaching Material and Method (11), 39-42. 